\title{
Endoscopic removal of an impacted acupuncture needle in the duodenum
}

A 49-year-old Korean woman was admitted to our hospital for treatment of hemorrhoids with intermittent bloodtinged stool since 5 months. She had had cerebral infarction 10 months ago, for which she was treated with traditional Chinese medicine including acupuncture therapy in the facial region. A detailed history could not be taken because of confusion of orientation and aphrasia. Her vital signs were stable, with normal abdominal and chest examination and laboratory tests. However, a hyperdense, linear, pin-like foreign body was incidentally found in the right upper abdominal area in a simple abdominal X-ray performed as part of the preoperative investigation ( Fig. 1). An abdominal computed tomography (CT) scan showed the foreign body was located in the second portion of the duodenum ( $\bullet$ Fig. 2). Subsequently, a transparent cap-fitted upper gastrointestinal endoscopy revealed a needle-like foreign body embedding into the mucosa of the second portion of the duodenum ( $\bullet$ Fig. 3). The proximal part of the foreign body was firmly grasped with biopsy forceps and slow traction applied into the cap of the endoscope as it was carefully withdrawn ( Fig.4). The foreign body was a 6-cm long acupuncture needle consisting of two parts: a $40 \times 0.25 \mathrm{~mm}$ thin, acupuncture part proximally located at the duodenum and a distally located $20 \times 1 \mathrm{~mm}$ thick, strap part ( Fig.5). There was no significant complication associated with either the presence of the foreign body or the endoscopic procedure. Such cases are extremely rare in the published literature [1-3].

Endoscopy_UCTN_Code_CCL_1AB_2AF

Competing interests: None

\section{J. M. Yun ${ }^{1}$, W. Moon ${ }^{2}$, J. H. Roh ${ }^{1}$}

${ }^{1}$ Department of Internal Medicine, Dong-Eui Medical Center, Busan, Korea

${ }^{2}$ Department of Internal Medicine, Kosin University College of Medicine, Busan, Korea

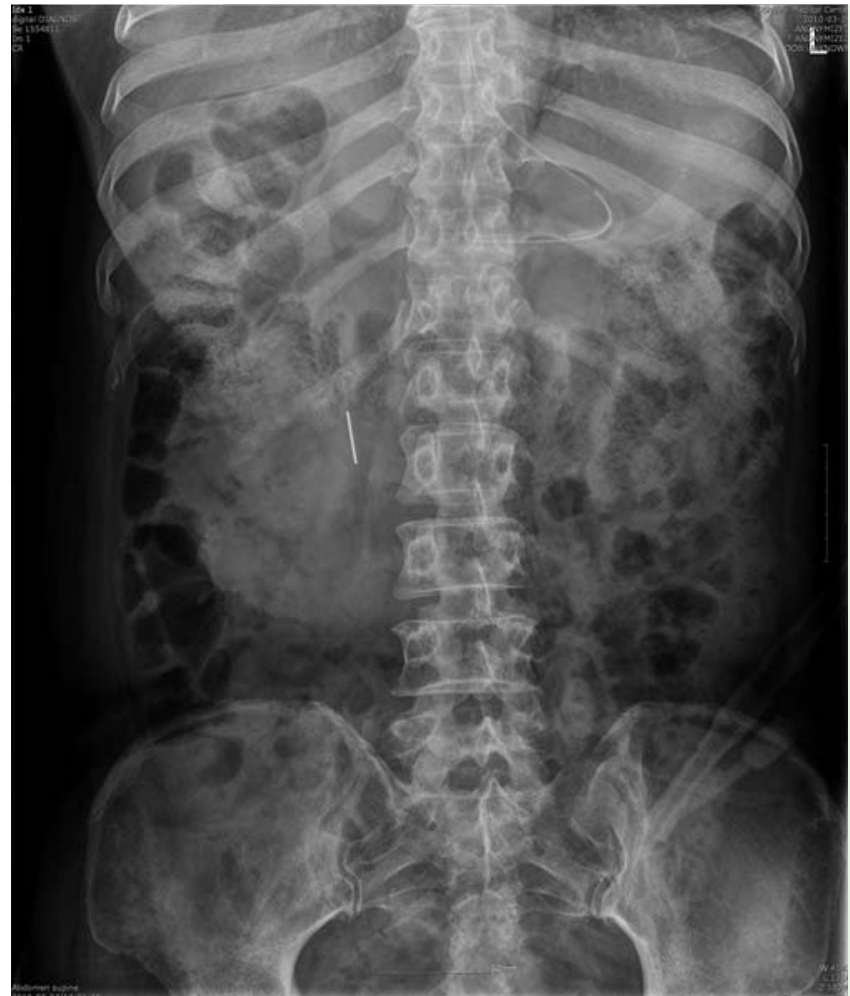

Fig. 1 Simple abdominal X-ray showing a hyperdense, linear, pinlike foreign body in the right upper abdominal area in an older woman with hemorrhoids and intermittent blood-tinged stool.

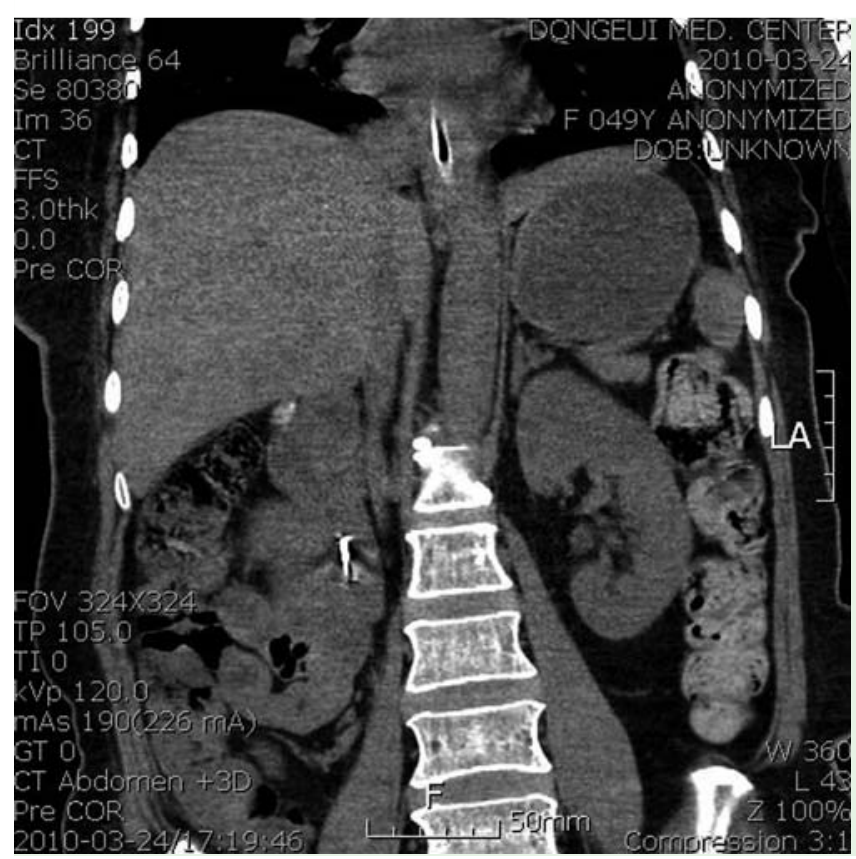

Fig. 2 An abdominal computed tomography (CT) scan confirmed the location of the foreign body in the second part of the duodenum. 


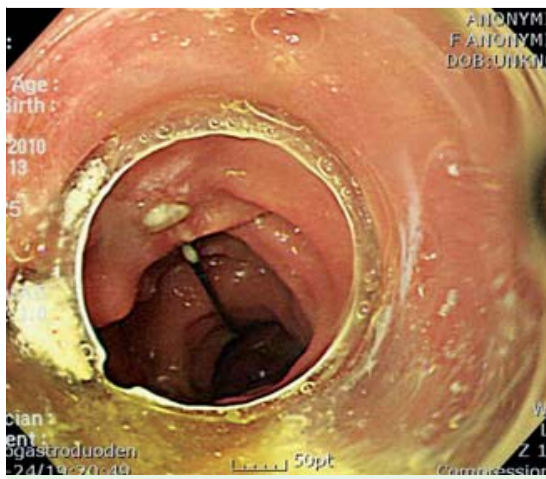

Fig. 3 Cap-fitted upper gastrointestinal endoscopic view showing a needle-like foreign body embedding into the mucosa of the second part of the duodenum.

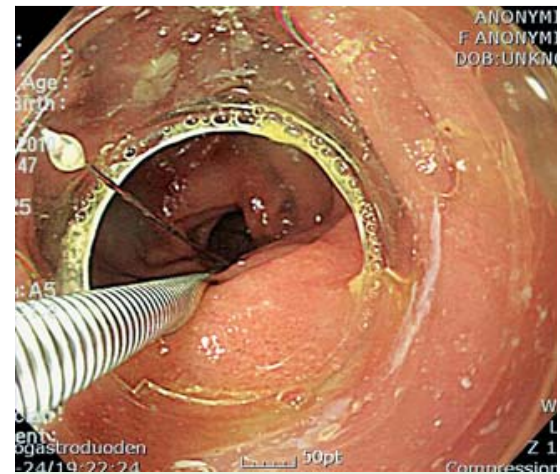

Fig. 4 Endoscopic view of the needle-like foreign body being moved into the cap before endoscopic withdrawal.

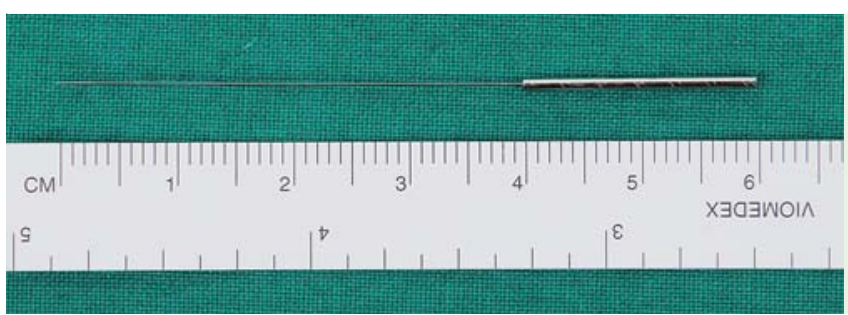

Fig. 5 The endoscopically removed 6-cm long acupuncture needle.

\section{References}

1 Velitchkov NG, Grigorov GI, Losanoff JE et al. Ingested foreign bodies of the gastrointestinal tract: retrospective analysis of 542 cases. World J Surg 1996; 20: 1001 - 1005

2 Gracia C, Frey CF, Bodai BI. Diagnosis and management of ingested foreign bodies: a ten-year experience. Ann Emerg Med 1984; 13: $30-34$

3 Webb WA. Management of foreign bodies of the upper gastrointestinal tract: update. Gastrointest Endosc 1995; 41: 39-51

\section{Bibliography}

DOI http://dx.doi.org/

10.1055/s-0031-1291571

Endoscopy 2012; 44: E106-E107

(c) Georg Thieme Verlag KG

Stuttgart · New York

ISSN 0013-726X

\section{Corresponding author}

\section{W. Moon}

Department of Internal Medicine Kosin University College of Medicine 34 Amnam-dong

Seo-gu

Busan 602-702

Korea

Fax: +82-51-9903005

moonone70@hanmail.net 